\title{
Clinical Research:
}

\author{
Boundaries and Standards
}

"RESEARCH" in clinical journals has traditionally meant original investigation concerning the biology of health and disease. The investigation has often been carried out in laboratories. Most of this research bears some relationship to the work of clinicians, but the relationship is often indirect and sometimes quite tenuous. Nevertheless, it has been the custom to call all this work, somewhat generously, "clinical research" if it takes place in medical centers and is published in clinical journals. A smaller proportion of clinical research concerns the disordered biology of intact humans. This kind of research can guide clinical decision-making much more directly. In any case, human biology is of paramount importance to clinicians. So it is reasonable that much of clinical research, including that published in the JOURNAL, emphasizes biology.

But many aspects of clinical work are not purely biologic. Over the past several decades, in response to strong, practical social demands, health services research - studies of how the organization and financing of medical care affect people's health - has begun to take a place in the mainstream of research for clinicians. Still other aspects of medical practice involve value judgments (ethics), culture (anthropology/sociology), history, law, politics, and many other perspectives. These aspects of clinical practice, as well as medical education, should be guided and improved by the best available evidence, from research.

How should research involving non-biologic disciplines be accommodated in a clinical journal? What kind of review process should this research pass through?

Most clinical journals limit the number of nonbiologic studies they publish and then set them apart from biologic research, labelling them "special articles," "perspectives," and the like. This practice probably both reflects and creates opinion about the work. Some of the consequences, perhaps unintended, are unfortunate. The separateness may imply that the work is less directly relevant to clinical medicine. It also suggests that the studies are judged by different standards. This attitude may well extend to tenure and promotion committees, who generally regard non-biologic clinical research as less scholarly than biologic research.

In the Journal of General InTERnal Medicine, we hope to publish reports of any kind of research that can guide clinical decision-making. General internists, mony of them members of SREPCIM, embrace a rich array of research interests. We want the JOURNAL to be a forum for their work. We also want to judge the work by criteria that are neither more nor less lenient than the standards applied to the more traditional kinds of clinical scholarship.

That is the Journal's aim. But the ideals are difficult to put into practice. In trying to do so, we have uncovered many questions. What are the standards for original research in the social sciences and humanities? Who can and should judge the work? What is original and what is secondary research?

The editorial staff has sought answers to these questions in several ways. Our colleagues in the University of North Carolina Clinical Scholars Program reviewed the literature on research standards in non-biologic disciplines. A portial product of this undertaking is an Annotated Bibliography on Interdisciplinary Research (pages 204-206). We informally surveyed senior faculty at our University whose disciplines were administratively located outside the Medical School but included, at least in part, studies of health and medical care. Finally, we hove learned from the review process for manuscripts already submitted to the JouRNAL. The result is that we know more, but questions remain. We will share what we found, hoping that will stimulate a useful discussion among our readers.

What are the standaras for scholarship in nonbiologic research? In our search, we found universal themes: important questions, addressed by sound methods, clearly described, with conclusions based on the evidence. The sticking point is "sound methods." What are they?

Many non-biologic clinical research papers are based in the "social sciences." For them, it seems to us that the soundest methods are very similar to those in other sciences: making a priori hypotheses, then collecting data and seeing if the hypotheses stand or fall.2. 3 The process involves fair sampling from a defined population, reliable and valid measurements, comparing like with like, estimating the role of chance in observed relationships, and so on. These principles apply across all scientific disciplines, biologic and social. Of course, tactics may vary. Some research is purely descriptive, and need not begin with hypotheses. Other resecrch is intended only to raise hypotheses, and not test them (although we should all be dissatisfied stopping there). Social (and particularly qualitative) research may use different methods of measurement than the biologic sciences, but the work should otherwise involve the same principles. 
And we are reminded that the actual performance of scientific research has many other dimensions: imagination, fashion and conservatism ${ }^{2}$ as well as arrogance and deception..$^{4,5}$ But these realities do not change what we should strive for.

It has been more difficult to oversee the scholarly review of clinically important work that is not scientific - work in the humanities or arts. How should we judge that kind of scholarship when it is sent to the JOURnal? So for, we have sent the work to clinicians, or their associates, with special interest and training in the relevant discipline. They have prepared thoughtful reviews and we have paid careful attention to their advice. But we remain dissatisfied because we are still not clear in our own minds what the ground rules are for review of this kind of scholarship.

Who should judge non-biologic research? Some experts say that any well-educated, intelligent fairminded person can understand research outside his field - to a point - and participate in judging it. Other experts in non-biologic disciplines say that there is no way outsiders can understand and judge their work without putting in the years of training necessary to become experts themselves. They say, in effect, "It's not for you to know. Trust us. We'll tell you if it's good." This approach worries us. The review process - or for that matter the work itself - should not be a "black box" for our readers and reviewers, most of whom are intellectually vigorous clinicians. If they make $a$ fair effort to understand the work and cannot, something is wrong - at least for the purposes of this JOURNAL.

Finally, what is original research and what is a review of other, existing information? The distinction can be difficult. For example, what about "meta-analysis" (information synthesis), a new generation of highly disciplined, critical reviews of published research, based on scientific principles embodied in clinical epidemiology, biostatistics and quantitative decision-making? What about penetrating analyses of ethical problems that are well-informed, internally consistent, and based on sound principles? Henry Perkins told us that his article "Ethics at the End of Life"6 (p.170) should not be considered original research. What about a wellresearched and documented historical essay? Is this type of work original research? We are uncertain.

Those responsible for the JOURNAL are anxious to avoid artificial distinctions among the various kinds of scholarships, both in review process and presentation. We hope our readers will play an important role in answering some of the questions we have raised. When you submit work tell us where you think it fits in - and why. Give us your suggestions in other ways. The JOURNAL should strive to find the best possible way to include research, without regard to the underlying discipline from which it arises, if it is of high quality and important to the work of clinicians. - Robert H. Fletcher, MD, and Suzanne W. Fletcher, MD, Editors

\section{REFERENCES}

1. Dittus R. Interdisciplinary research. An annotated bibliography. J Gen Intern Med 1986:1:204-206

2. Chalmers AF. What is this thing called science? Second edition. Queensland: University of Queensland Press. 1982

3. Platt JR. Strong inference. Science 1964;146:347-53

4. Broad W, Wade N. Betrayers of the truth. New York, Simon and Schuster, Inc., 1982

5. Mahoney MJ. Scientist as subject: the psychological imperative. Cambridge, Massachusetts: Ballinger, 1976

6. Perkins $H$. Ethics at the end of life. $J$ Gen Intern Med 1986;1:170-176

\title{
ANNOTATED BIBLIOGRAPHY
}

\section{Interdisciplinary Research}

\author{
ROBERT S. DITTUS, MD, MPH
}

THIS BIBLIOGRAPHY provides an initial access to the literature concerning the conduct of research that crosses the boundaries between two or more traditional schools of thought. Such research implies the coordination of two or more persons whose dis-

Received from the Division of General Internal Medicine and Regenstrief Institute for Health Care. Department of Medicine. Indiana University School of Medicine. Indianapolis, Indiana.

Address correspondence and reprint requests to Dr. Dittus: Regen strief Institute for Health Care, 1001 West 10th Street, Indianapolis, IN 46202 . ciplines and academic identities differ. The term "interdisciplinary research" refers to on investigative approach to the solution of a problem that no individual discipline can adequately devise; it demands the continuous integration of paradigms, strategies, and techniques of related fields. The problems addressed by investigators in general medicine frequently require interdisciplinary research for solution.

The conduct of interdisciplinary research presents to both research administrators and partici- 